\title{
Gulf Stream Variability in Five Oceanic General Circulation Models
}

\author{
Gä̈lle de Coëtlogon,* Claude Frankignoul, ${ }^{+}$Mats Bentsen, ${ }^{*}$ Claire Delon, ${ }^{@}$ \\ Helmuth HaAk, \& Simona Masina, ${ }^{* *}$ and Anne Pardaens ${ }^{++}$ \\ *Centre d'Etude Terrestre et Planétaire, IUT de Vélizy, Vélizy, France \\ + Laboratoire d'Océanographie Dynamique et de Climatologie, Université Pierre et Marie Curie, Paris, France \\ \#Nansen Environmental and Remote Sensing Center, Bergen, Norway \\ ${ }^{\circledR}$ Laboratoire d'Aérologie, Observatoire Midi Pyrénées, Toulouse, France \\ ${ }^{\star}$ Max Planck Institute for Meteorology, Hamburg, Germany \\ **Istituto Nazionale di Geofisica et Vulcanologia, Bologna, Italy \\ ++ Hadley Centre for Climate Prediction and Research, Met Office, Exeter, United Kingdom
}

(Manuscript received 22 December 2004, in final form 28 March 2006)

\begin{abstract}
Five non-eddy-resolving oceanic general circulation models driven by atmospheric fluxes derived from the NCEP reanalysis are used to investigate the link between the Gulf Stream (GS) variability, the atmospheric circulation, and the Atlantic meridional overturning circulation (AMOC). Despite the limited model resolution, the temperature at the 200-m depth along the mean GS axis behaves similarly in most models to that observed, and it is also well correlated with the North Atlantic Oscillation (NAO), indicating that a northward (southward) GS shift lags a positive (negative) NAO phase by $0-2$ yr. The northward shift is accompanied by an increase in the GS transport, and conversely the southward shift with a decrease in the GS transport. Two dominant time scales appear in the response of the GS transport to the NAO forcing: a fast time scale (less than 1 month) for the barotropic component, and a slower one (about $2 \mathrm{yr}$ ) for the baroclinic component. In addition, the two components are weakly coupled. The GS response seems broadly consistent with a linear adjustment to the changes in the wind stress curl, and evidence for baroclinic Rossby wave propagation is found in the southern part of the subtropical gyre. However, the GS shifts are also affected by basin-scale changes in the oceanic conditions, and they are well correlated in most models with the changes in the AMOC. A larger AMOC is found when the GS is stronger and displaced northward, and a higher correlation is found when the observed changes of the GS position are used in the comparison. The relation between the GS and the AMOC could be explained by the inherent coupling between the thermohaline and the wind-driven circulation, or by the NAO variability driving them on similar time scales in the models.
\end{abstract}

\section{Introduction}

Temperature observations show that the main mode of the low-frequency variability of the Gulf Stream (GS) is a meridional displacement of its axis, and empirical studies suggest that the large-scale GS fluctuations are mostly atmospherically forced. Taylor and Stephens (1998) showed that the GS shifts were correlated with the wintertime North Atlantic Oscillation (NAO), with a positive (negative) phase of the NAO being followed by a northward (southward) GS dis-

Corresponding author address: Gaëlle de Coëtlogon, Centre d'Etude Terrestre et Planétaire, IUT de Vélizy, 10-12 avenue de l'Europe, 78140 Vélizy, France.

E-mail: gdc@cetp.ipsl.fr placement 2-3 yr later. Using temperature observations at the 200-m depth between 1954 and 1990, Joyce et al. (2000) found that the correlation with the NAO during winter was maximal at zero lag or with GS lagging by 1 yr. Extending the data to 1998, Frankignoul et al. (2001, hereinafter FCJD) showed that the correlation was maximal when the GS was lagging the NAO by about 1 $\mathrm{yr}$, consistent with an analysis of $6 \mathrm{yr}$ of monthly Ocean Topography Experiment/Poseidon data.

Except on the seasonal scale (Tracey and Watts 1986), dynamic height differences across the GS suggest that a northerly (southerly) path of the GS corresponds to a larger (weaker) eastward GS transport (Rossby and Rago 1985), consistent with Geosat data (Kelly and Gille 1990; Kelly 1991; Zlotnicki 1991). Some observational studies show substantial low-frequency variabil- 
ity in the GS transport. For instance, the diagnostic calculation with the observed density data of Greatbach et al. (1991) suggested that the barotropic GS transport was considerably weakened by about $30 \mathrm{~Sv}$ $\left(\mathrm{Sv} \equiv 10^{6} \mathrm{~m}^{3} \mathrm{~s}^{-1}\right)$ during 1970-74 when compared with that of $1955-59$, primarily resulting from a change in the joint effect of baroclinicity and relief. Note, however, that serious doubts have been raised on the reliability of such a calculation with limited data (Cane et al. 1998), which was furthermore based on a simplifying assumption (linearity, no mixing or Reynolds stresses) that may not apply to the GS region. Using a large number of hydrographic sections, Sato and Rossby (1995) estimated that the decrease in the baroclinic transport was $6 \mathrm{~Sv}$ for the same period of time, and they found that their best sample pentads were within $4 \mathrm{~Sv}$ of each other. Curry and McCartney (2001) gave observational evidence that the interannual-to-interdecadal variability of the intensity of the North Atlantic gyre circulation largely reflected the integral response of the ocean to the NAO forcing in the subtropical and subpolar gyres, but the contribution of the wind and the buoyancy forcing was hard to separate.

Different mechanisms have been suggested to explain the origin of this variability. The Parsons (1969) and Veronis (1973) two-layer steady-state models suggest that the wind stress controls the latitude where the GS leaves the coast. The adjustment to a wind stress change is determined by Rossby wave propagation and thus, in the linear, flat-bottomed framework, should take a week or so for the barotropic transport and several years for the baroclinic transport (Sirven 2005), consistent with the 3-yr delay found in frontal analysis of the sea surface temperature field by Gangopadhyay et al. (1992). A good prediction of the GS position was obtained from the meridional displacement of the wind stress curl associated with the NAO by Taylor and Gangopadhyay (2001), using temperature advection and linear dynamics. Ocean-atmosphere heat exchanges in the GS region could also modify the GS strength and the latitude of the separation path (Nurser and Williams 1990). Last, inertial effects result in both intrinsic variability (Jiang et al. 1995) and different response modes to wind forcing than via linear baroclinic Rossby waves, as explored by Dewar (2003). As shown for the Kuroshio extension by Taguchi et al. (2005), inertial effects and eddy mean flow interaction can also substantially strengthen the response of a western boundary current to remote forcing by the wind.

An alternative explanation of the GS shifts involves the interaction of the wind-driven circulation with changes in the thermohaline circulation. This can be investigated using oceanic general circulation models
(OGCMs). However, the GS transport is much too weak in non-eddy-resolving OGCMs, and the GS does not separate from the coast at Cape Hatteras, but follows the continental shelf until the Grand Banks, leaving no space for the slope sea and the observed northern cyclonic circulation cell. This happens because inertial effects and the recirculation gyres (e.g., Cessi 1990) are not well represented, and the influence of the bottom pressure torque (Holland and Hirschman 1972) is underestimated because the deep western boundary current (DWBC) is generally too weak, resulting in an underestimation of the GS transport. As mentioned before, Greatbach et al. (1991) and Ezer et al. (1995) have suggested that changes in the deep circulation were responsible for the large changes in the GS transport that they estimated. By enhancing the Denmark Strait overflow water, Gerdes and Köberle (1995) showed that the intensification of the DWBC lead to a southward shift of the GS path, an intensification of the meridional overturning, and a much stronger GS associated with an enhanced northern recirculation gyres. Sensitivity studies with eddy-permitting regional models also suggest that the presence of a strong barotropic slope water inflow in the northern recirculation gyre causes the GS to separate further south (Ezer and Mellor 1992; Gerdes et al. 2001). The same effect is caused by the presence of a strong upper core of the deep western boundary current (Spall 1996). Whether such idealized sensitivity studies can be used to infer that in realistic conditions an enhanced Atlantic meridional overturning circulation (AMOC) leads to a southward GS shift and an increase of its transport remains to be seen.

A few OGCM simulations have been made with more realistic forcing. Using an Atlantic model of intermediate resolution, Eden and Willebrand (2001) have shown that the variability of the North Atlantic circulation is primarily due to the NAO. The Ekman pumping associated with the NAO caused a fast barotropic response resembling a Sverdrup balance together with a direct AMOC response, followed after about $3 \mathrm{yr}$ by an intensification (for a positive NAO phase) of the subpolar and subtropical gyres and a baroclinic AMOC response. The cooling in the Labrador Sea enhanced the deep convection and lead to a strengthening of the subpolar gyre and AMOC after 2-3 yr, followed by the southward propagation of the latter. On interdecadal time scales both the thermohaline circulation and the subpolar and subtropical gyre strength were responding to the NAO changes (primarily via surface heat exchanges), with an enhanced meridional and horizontal circulation lagging a positive NAO phase by 10-20 yr (Eden and Jung 2001). In a short eddy-resolving simulation, Penduff et al. (2004) showed that the GS and its 
eddy field were modulated by the NAO, with a stronger GS located further north following a positive NAO phase by 4-12 months, which is consistent with the observed GS displacements (FCJD) and the hypothesis of Kelly (1991), although the adjustment is somewhat faster. They suggested that both the eddy dynamics and the large-scale forcing play a role in the adjustment. Lacking sufficiently long simulations, however, the link between AMOC and GS has not been investigated in eddy-resolving models, and the observational evidence is not sufficient to document it in the observations. Hence, it remains of interest to consider it in non-eddyresolving OGCM runs, in particular when forced by atmospheric fluxes derived from the observations.

In the present paper, we consider five OGCM simulations performed as part of the Mechanisms and Predictability of Decadal Climate Fluctuations in AtlanticEuropean Climate (PREDICATE) project of the European Union. As the models mostly correspond to the oceanic component of global climate models, they have a limited resolution and they neither resolve the mesoscale eddies nor correctly represent the influence of nonlinearity. Nonetheless, a comparison with the observations should provide useful information on the direct influence of the atmospheric forcing and the link between GS changes and the AMOC. In addition, the comparison provides a test of validity for the ocean models and thus the climate models that use them as an oceanic component.

\section{The OGCM simulations}

The global ocean models used in this study were as follows: Océan Parallélisé [OPA, version 8.1], the Modular Ocean Model (MOM), the Max Planck Institut Ocean Model (MPI-OM), the Miami Isopycnal Coordinate Ocean Model (MICOM), and the third-generation Hadley Centre Ocean Model (HadOM3). OPA (Madec et al. 1998) was run at the Centre Européen de Recherche et de Formation Avancée en Calcul Scientifique (CERFACS) with an extratropical resolution of about $2^{\circ}$ latitude $\times 2^{\circ}$ longitude and 31 vertical levels (L31). MOM (Cox 1985) was run at the Instituto Nazionale di Geofisica e Vulcanologia (INGV) at $0.5^{\circ} \times$ $0.5^{\circ}$ resolution with L31 (Masina et al. 2004). MPI-OM (Marsland et al. 2003) was run at MPI in Hamburg, Germany, with a resolution of $20-100 \mathrm{~km}$ in the North Atlantic with 40 vertical levels (L40) (Haak et al. 2003). MICOM (Bleck et al. 1992) was run at the Nansen Environmental and Remote Sensing Center with a resolution of about $80 \mathrm{~km}$ in the midlatitudes with 26 vertical levels (L26) (Bentsen et al. 2004). HadOM3
(Gordon et al. 2000) is the ocean component of the third Hadley Centre Coupled Ocean-Atmosphere General Circulation Model. It was run as a forced OGCM at the Met Office with a resolution of $1.25^{\circ} \times$ $1.25^{\circ}$ and 20 vertical levels (L20). All models included an embedded sea ice model.

After spinup, each model was forced by atmospheric fluxes derived from 24-hourly atmospheric fields in the National Centers for Environmental PredictionNational Center for Atmospheric Research (NCEPNCAR) reanalysis (Kalnay et al. 1996): 10-m wind, 2-m air temperature, 2-m humidity, total cloudiness, and precipitation. There is an implicit restoration on the observed sea surface temperature via the bulk formulas for the turbulent heat fluxes. OPA and MICOM were run with a fixed freshwater correction flux diagnosed from their spinup, but no feedback on the surface salinity. MOM, MPI-OM, and HadOM3 were run with a Newtonian relaxation toward the surface salinity climatology of Levitus (1994) with a time scale of 50, 180, and 300 days, respectively. The simulations started in 1948 (1958 for MOM). Nine runs based on different initial oceanic conditions derived from successive simulations were available for MPI-OM, four for MICOM, and one for the other models.

\section{Gulf Stream variability}

In FCJD, the GS position during 1954-98 was monitored between $75^{\circ}$ and $55^{\circ} \mathrm{W}$ by the changes in the yearly averaged temperature along the mean position of the $15^{\circ} \mathrm{C}$ isotherm at $200-\mathrm{m}$ depth, which corresponds to the northern wall of the GS and is always below the surface mixed layer. The mean GS position is superposed in Fig. 1a (top; thick dashed line) to the Levitus climatology (Levitus 1994; gray shading). Note that the location of the $15^{\circ} \mathrm{C}$ isotherm differs slightly in the two datasets because of the differences in data selection, interpolation, smoothing, and temporal coverage. The main mode of variability of the GS position, as derived by FCJD from an empirical orthogonal function (EOF) analysis, was a nearly spatially uniform warming or cooling (top; thick continuous line), which corresponded to a northward or southward shift of the GS axis. The time behavior showed primarily decadal fluctuations superimposed onto a fast southward shift until the late 1950s and a slow northward shift after the mid-1960s (Fig. 1a, bottom), and the analysis suggested that the GS primarily responds as an integrator of the wind stress curl changes associated with the NAO variability-a northern (southern) GS lagging a positive (negative) NAO phase by about 1 yr (shown in Fig. 3a below). 
a) OBS (XBT): GS iso. $15^{\circ} \mathrm{C} 200(49 \%)$

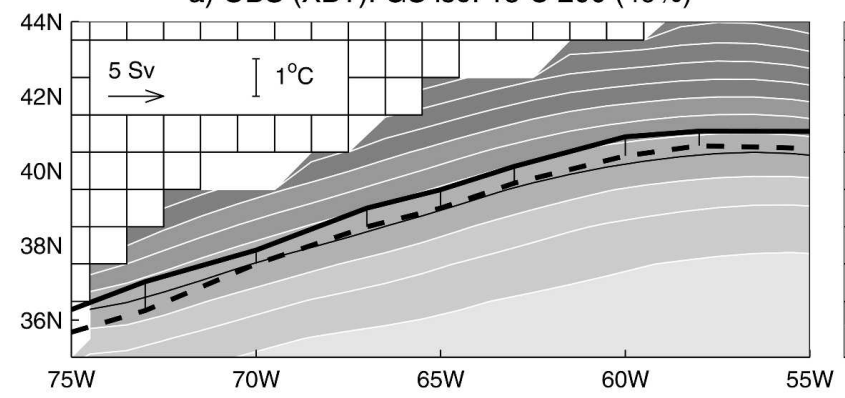

d) MPI-OM: GS iso. $17^{\circ} \mathrm{C}(75.5 \%)$
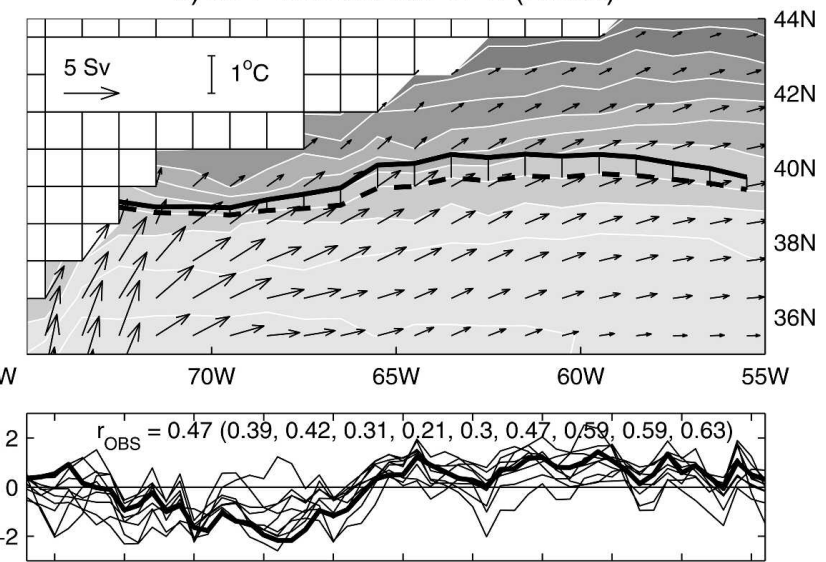

b) OPA: GS iso. $15{ }^{\circ} \mathrm{C}(70.4 \%)$

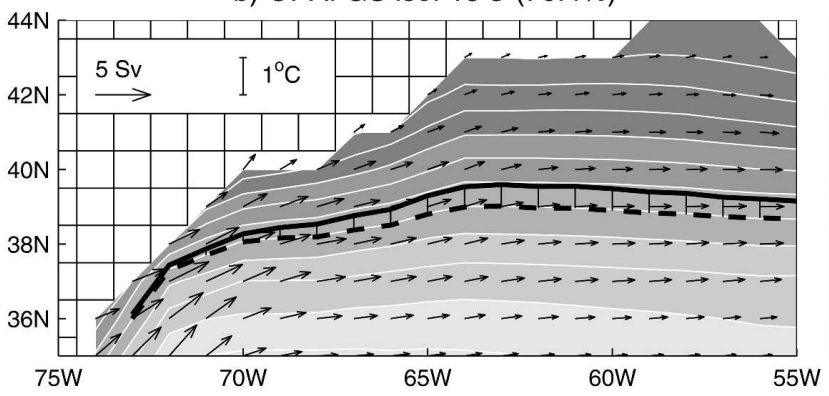

e) MICOM: GS iso. $16^{\circ} \mathrm{C}(61.1 \%)$

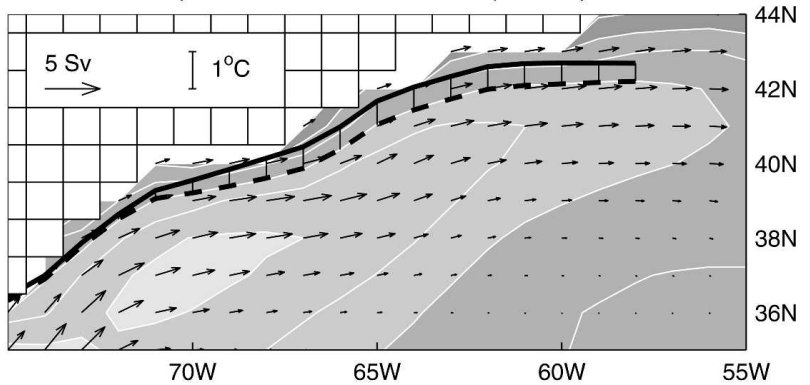

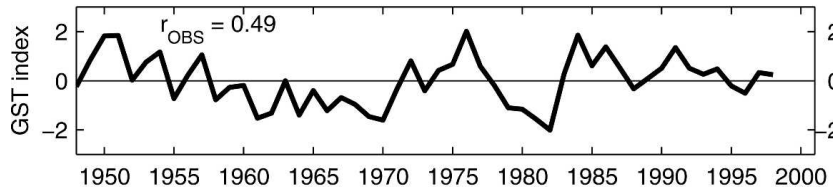

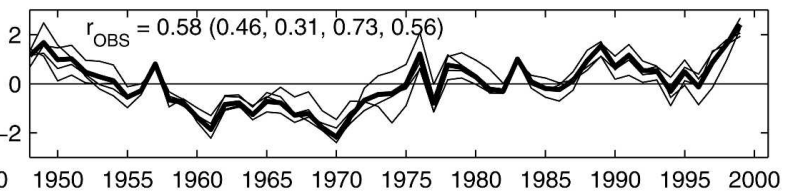

c) MOM: GS iso. $16^{\circ} \mathrm{C}(60.5 \%)$

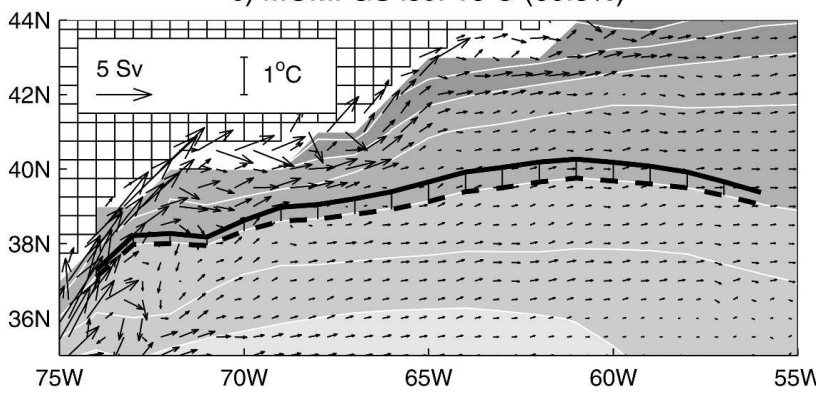

f) HadOM3: GS iso. $15^{\circ} \mathrm{C}(60.7 \%)$

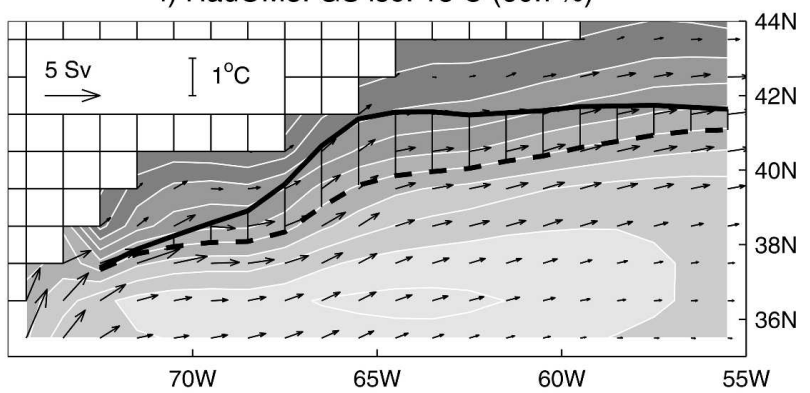

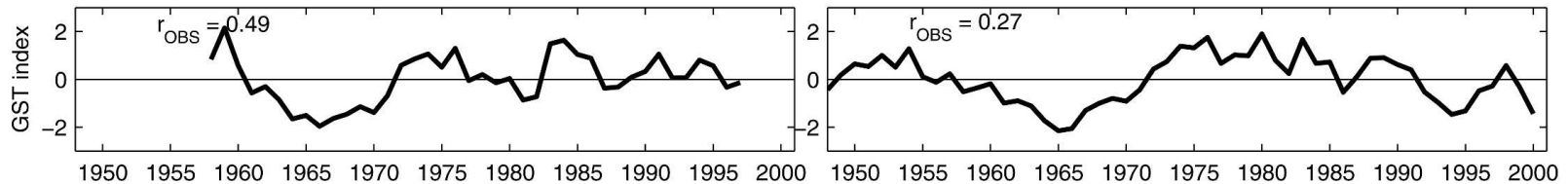

FIG. 1. For the observations and each OGCM (top) mean temperature at the 200-m depth (grayscale), mean transport between the 200- and 600-m depth (arrows, models only; Sv), chosen mean position for the Gulf Stream (heavy dashed), and first EOF of the temperature along the mean Gulf Stream position (solid; ${ }^{\circ} \mathrm{C}$ ) are shown. The explained percentage of variance is indicated. (bottom) The (normalized) first principal component time series of GST index for each simulation. The correlation with the observed GS index is given (in parentheses, correlation for each simulation of an ensemble). 
In the models, the position of the GS is not well defined because of their limited resolution, and the mean temperature gradient is much too small, although it is slightly more realistic in MOM, whose grid size is closer to the eddy scale (Figs. 1b-f). Correspondingly, the GS is much too broad, as illustrated for the horizontal transport between the 200- (under the Ekman layer) and 600-m depth (generally above the thermocline). Because the eddies are not resolved, the GS transport is much too weak; the mean barotropic transport is typically of about $20 \mathrm{~Sv}$, as compared with about $100 \mathrm{~Sv}$ in the observations (up to $150 \mathrm{~Sv}$ around $65^{\circ} \mathrm{W}$ ). This difference is largely due to the lack of a recirculation gyre north and south of the GS. The simulations exhibit another classical flaw of the low-resolution oceanic models, as the GS does not separate from the coast at Cape Hatteras, but rather follows the coast further north.

To facilitate the intercomparison, the data were interpolated on a $1^{\circ} \times 1^{\circ}$ grid, except for MOM where the $0.5^{\circ}$ grid size was kept. Because the four simulations with MICOM and the nine simulations with MPI-OM had a fairly similar climatology, only the ensemble mean is plotted in Fig. 1. In each simulation, monthly temperature and transport anomalies were computed by removing the mean seasonal cycle. An annual index of the GS position was also constructed for each model in the same way as in FCJD, even though the choice of the reference isotherm at $200 \mathrm{~m}$ to define the GS axis is rather arbitrary in view of the large width of the western boundary flow. In the observations, the $15^{\circ} \mathrm{C}$ isotherm at $200 \mathrm{~m}$ corresponds to the northern wall of the GS, while the $17^{\circ} \mathrm{C}$ isotherm better corresponds to the location of the maximum surface current, so that either isotherm could have been used. Depending on the models, the yearly averaged temperature anomalies were thus interpolated at $1^{\circ}$ longitude interval along the mean position of the $15^{\circ}, 16^{\circ}$, or $17^{\circ} \mathrm{C}$ isotherm. Indeed, the $15^{\circ} \mathrm{C}$ isotherm was too close to the coast in MICOM and $\mathrm{MOM}$, so that the $16^{\circ} \mathrm{C}$ isotherm was used instead to define the mean GS position. In MPI-OM, we used the $17^{\circ} \mathrm{C}$ isotherm where the mean temperature gradient was a maximum. However, changing the reference isotherm did not significantly influence the results for a given model.

For each model, an EOF analysis was performed on the temperature anomalies along the mean GS axis. The first EOFs are represented in Figs. 1b-f (top, in continuous line). In each case, the main mode of variability is a temperature increase (decrease) all along the mean GS path, corresponding to a north (south) shift of the GS position. The pattern is similar to that in the observations (Fig. 1a), except for the smaller amplitude west of about $70^{\circ} \mathrm{W}$. Note the larger percentage of represented variance, presumably because of the lack of mesoscale eddies in the models and the substantial amount of noise in the observations. The EOFs have the same typical amplitude of about $0.5^{\circ} \mathrm{C}$ as in the observations, except in HadOM 3 where it exceeds $1^{\circ} \mathrm{C}$, possibly in part because the $15^{\circ} \mathrm{C}$ isotherm at $200 \mathrm{~m}$ was located within the mixed layer during a substantial part of the year.

The (normalized) principal components or EOF time series, the Gulf Stream temperature (GST) index, are plotted in Fig. 1 (bottom), and their correlation $r_{\mathrm{obs}}$ with that observed (plotted in Fig. 1a) is given. For MICOM and MPI-OM, $r_{\text {obs }}$ is given for the ensemble mean and for each simulation separately. Although there are substantial differences with the observed behavior, the OGCM indices are generally fairly well correlated with the observed GST index, in spite of the fact that these low-resolution models strongly underestimate the GS transport. Because the models lack eddy dynamics and strongly underestimate the influence of nonlinearity, the good correlation suggests that the observed GS shifts are largely forced by the atmosphere at the interannual and decadal time scales.

When several simulations are available for a model, there is a substantial scatter in the correlation for each individual run, which may vary by a factor 2 or 3 . This points to a substantial influence of the initial oceanic conditions on the GS position. Moreover, the scatter does not decrease with time, as would be expected from the baroclinic adjustment of the subtropical gyre if the wind forcing was the sole mechanism at play (Anderson and Gill 1975). Lacking information on the true initial oceanic conditions, we will work with the ensemble mean of the MPI-OM and MICOM simulations, and keep in mind the expected scatter when only one simulation was performed. For instance, the correlation between the GST index in the HadOM3 simulation and the observed one is small (0.27), and only marginally statistically significant at best. However, this may be due to inadequate initial conditions, because one MICOM and three MPI-OM simulations have comparable values, while their averaged correlation is much higher. In view of the strong dependence on the initial conditions, we will not attempt to use this comparison to rank the different OGCMs.

To establish the link between the meridional shifts of the GS and the changes in its intensity, the 200-600-m transport was projected onto the GST index (Fig. 2). Near the western boundary of the subtropical gyre, the horizontal current is largely baroclinic, and the 200600-m transport will thus be used as a proxy for, and referred to as, the baroclinic transport (it was verified 


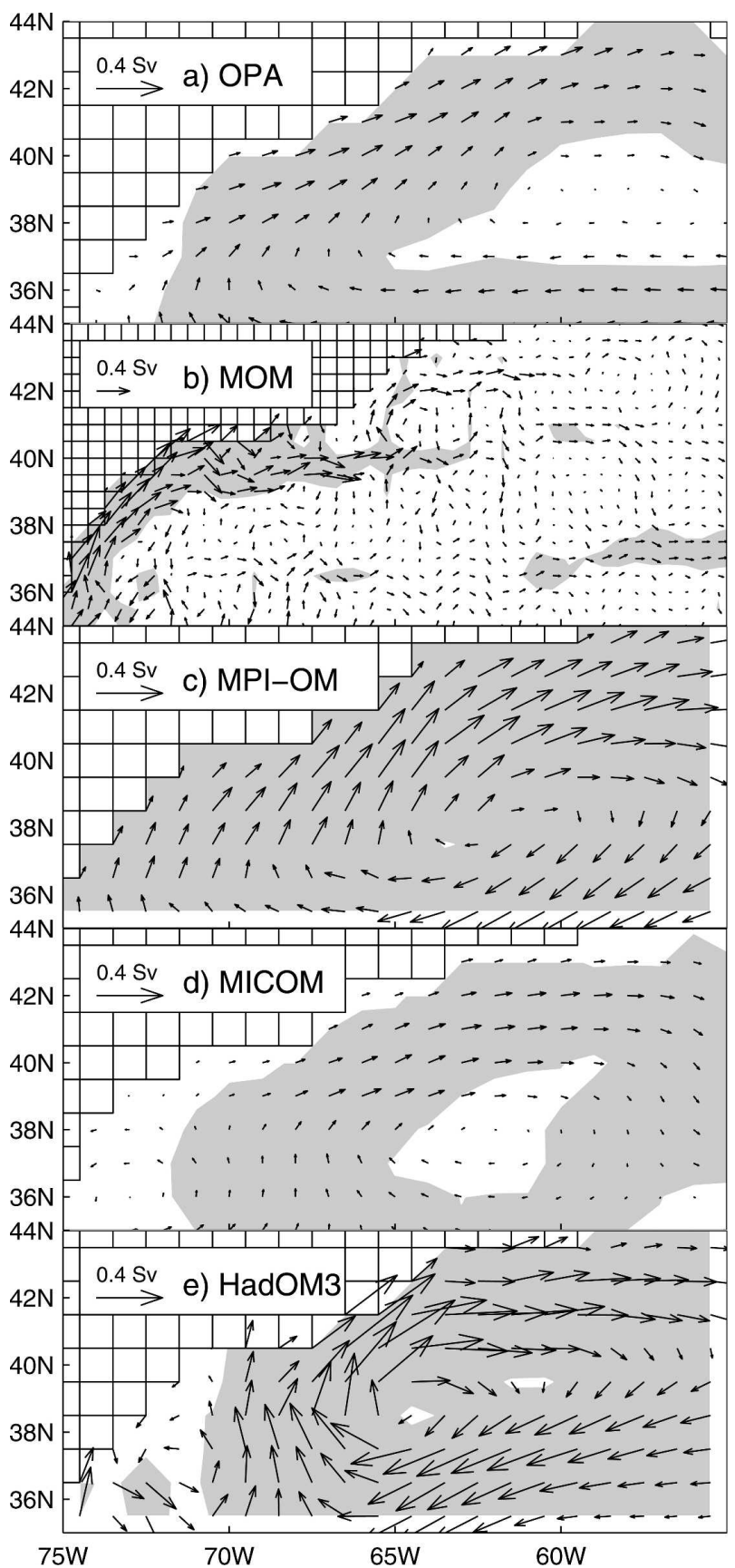

FIG. 2. Projection of 200-600-m transport on the Gulf Stream temperature index. Gray shading indicates where the correlation is $10 \%$ significant, assuming an independent sample every $2 \mathrm{yr}$.

that the barotropic contribution is negligible). The correlation between baroclinic transport and the GST index is generally high, even exceeding 0.9 in some areas (note that in the figures of this paper, the significance level was estimated by assuming for simplicity that the samples are independent). As shown by the regression in Fig. 2, a warming along the mean axis of the GS, and hence a northward shift, corresponds in each case to an increased baroclinic transport in the GS region. However, large differences between the models must be noted; in MICOM, OPA, and MOM, the increase in the northeastward GS transport and the associated return flow to the south is rather moderate, while it is larger in MPI-OM. The current system is somewhat different in HadOM3, with an even stronger anticyclonic gyre than in MPI-OM and a small cyclonic gyre in the southwestern part of the domain. Hence, the GS response seems more complex than predicted by simple adjustment theory to wind stress changes, because the latter are identical in each run. It is suggested in section 5 below that the GS fluctuations reflect in part basin-scale changes in the thermohaline circulation, which may also explain the long time dependence on the initial conditions.

\section{Link with the atmospheric forcing}

As recalled above, several observational studies have suggested that the meridional shifts in the GS position are mostly linked to previous NAO changes. Figure $3 \mathrm{a}$ reproduces from FCJD the lagged correlation between the GST index and a NAO index defined as the first principal component of monthly SLP anomalies in the North Atlantic sector from the NCEP-NCAR reanalysis. Statistical significance is estimated by assuming independent samples every year, which is a reasonable assumption for the NAO time series. The correlation is negligible when the GS leads, is large at zero lag, is larger when the GS follows by $1 \mathrm{yr}$, and then slowly decreases at larger lags, consistent with the statistical signature of a long time-scale system stochastically forced by the atmosphere. The correlation between the NAO and the GST indexes is shown for the different models in Figs. 3b-3f. In general, the cross correlation is a bit more rugged, but is rather similar to that observed-it is mostly negligible when the GS leads, is a maximum when the GS is in phase with the NAO or lags by $1 \mathrm{yr}$, and then slowly decreases at larger lags. An exception is HadOM3 where the GS position and the NAO are hardly correlated when the NAO leads by 1 yr. Although this correlation is more robust when colder (northern) isotherms are chosen (not shown), this result is not surprising because the GST index was poorly correlated with that observed, and the associated currents differed somewhat from those in the other models, which suggests that somewhat different dynamics may be at play.

In FCJD, the GST index was computed from the temperature data rather than currents, because of the sparsity of observed current data. However, the 


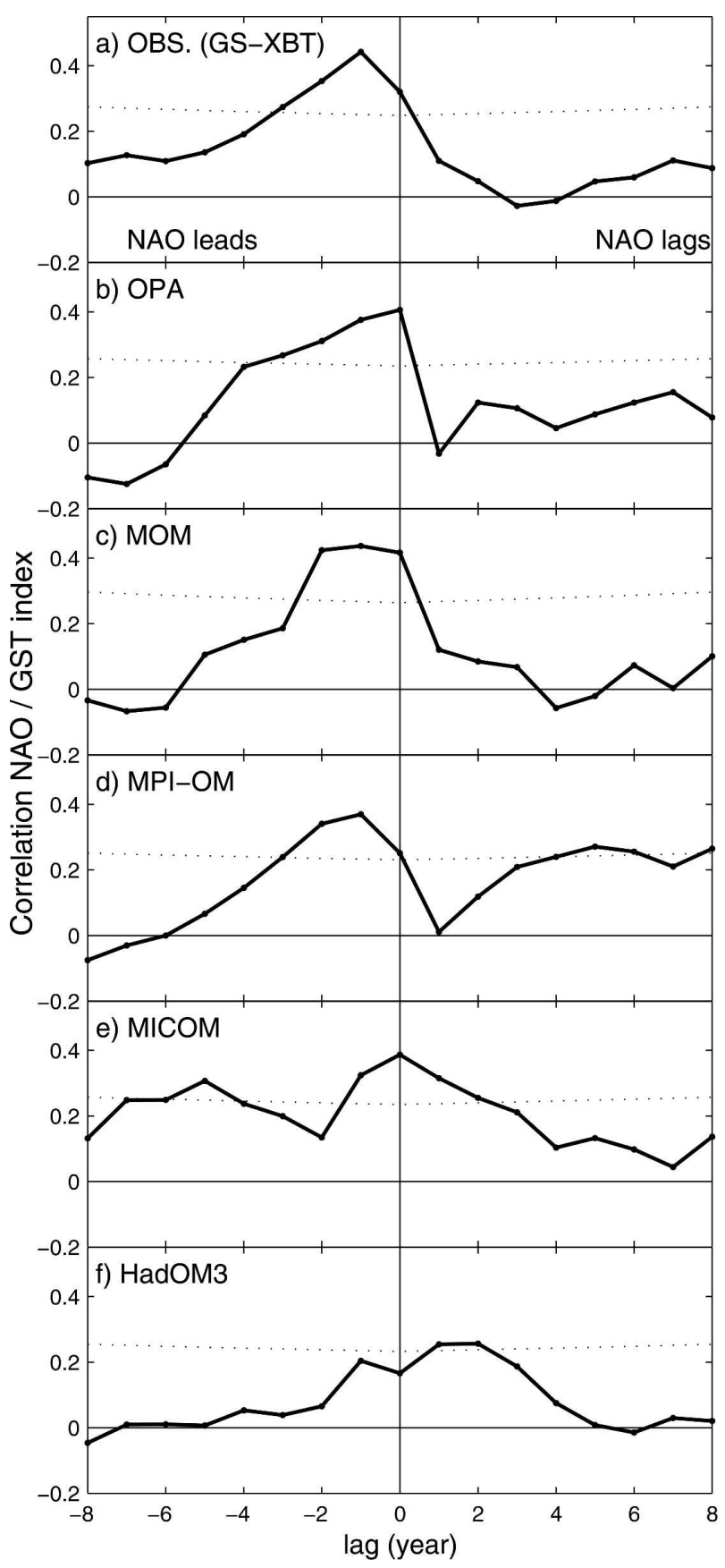

FIG. 3. Cross correlation between NAO and GST indices. The $10 \%$ level of significance for zero correlation is given by the dotted lines. NAO leads for negative lags.

changes in the GS transport in the models can be directly related to the atmospheric fluctuations, and they are more relevant than the temperature fluctuations along the mean GS axis, in view of the poor definition of the latter. The link between changes in the barotropic (i.e., depth integrated) and baroclinic transport and the atmosphere was thus investigated. We used various analysis methods, and both monthly and yearly averages. Because the results are similar but most informative when a maximum covariance analysis (MCA), based on singular value decomposition (e.g., von Storch and Zwiers 1999), was performed with monthly anomaly data, only the latter will be illustrated.

The MCA was applied to the transport anomalies in the small domain considered previously (Fig. 4, left column, and framed in middle column) and SLP anomalies in a broader North Atlantic sector (Fig. 4, middle column). In the MCA, each field is expanded into a series of orthogonal patterns that maximize the covariance between each pair of pattern. Here we will only show the first MCA mode, using so-called (Bretherton et al. 1992) homogeneous maps for the transport and heterogeneous maps for the atmosphere (i.e., the projection of both fields onto the transport time series). Robustness was assessed with a moving-blocks bootstrap approach. The MCA was repeated 100 times, linking the original transport dataset with randomly scrambled (by 2-month blocks) SLP ones, so that the chronological order between the two variables was destroyed. The quoted significance levels indicate the percentage of randomized square covariance and correlation for the corresponding mode that exceeded the value being tested.

For each model, the first MCA mode between monthly SLP and barotropic transport anomalies has a very sharp peak in square covariance at lag 0 . As shown in Fig. 4, the mode is highly significant and the correlation between the two time series is strong. The atmospheric maximum covariance pattern (middle column) corresponds in each case to the NAO in its positive phase, while the barotropic transport (left column) shows an increase in the GS transport. The relation is broadly consistent with the expected equilibrium barotropic response of the subtropical gyre to wind stress curl forcing by the NAO. The oceanic pattern varies somewhat between models, but in all cases shows a strong northeastward transport near the western boundary and hints of the southwestward flow that feeds it. The standard deviation of the barotropic transport induced by the NAO at $64^{\circ} \mathrm{W}$ varies somewhat from model to model: $2.6 \mathrm{~Sv}$ for HadOM, $2.5 \mathrm{~Sv}$ for OPA, 1.9 Sv for MPI-OM, and 1.4 Sv for MOM and MICOM. Because the maximum values are about 3 times larger, the range of variations is substantially smaller than the $30 \mathrm{~Sv}$ estimated by Greatbach et al. (1991) (see also Ezer et al. 1995), but is more in tune with the estimates of Sato and Rossby (1995).

The lagged relation between barotropic transport and NAO is clearly seen in the cross correlation between the two MCA time series (right column), which 
BAROTROP. TRANSP. OPA: $S C=258(0 \%) R=0.57(0 \%)$

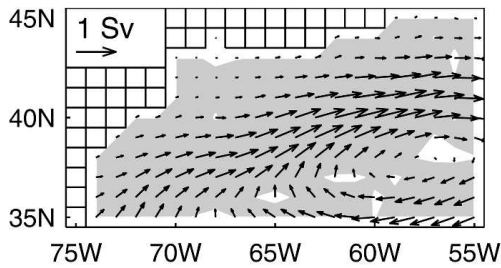

$75 \mathrm{~W} \quad 70 \mathrm{~W} 65 \mathrm{~W} 60 \mathrm{~W} 55 \mathrm{~W}$

MOM: SC $=592(0 \%) R=0.73(0 \%)$
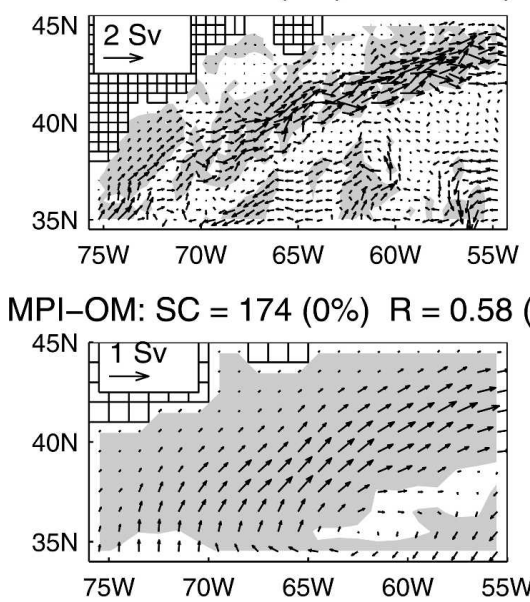

MICOM: SC $=224(0 \%) \mathrm{R}=0.68(0 \%)$

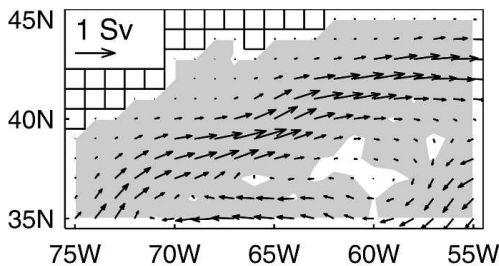

$75 \mathrm{~W} \quad 70 \mathrm{~W} \quad 65 \mathrm{~W} \quad 60 \mathrm{~W} \quad 55 \mathrm{~W}$
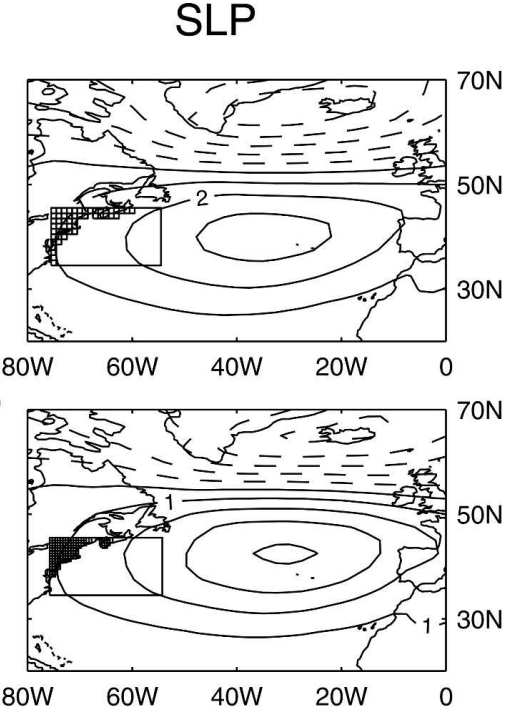
$80 \mathrm{~V}$
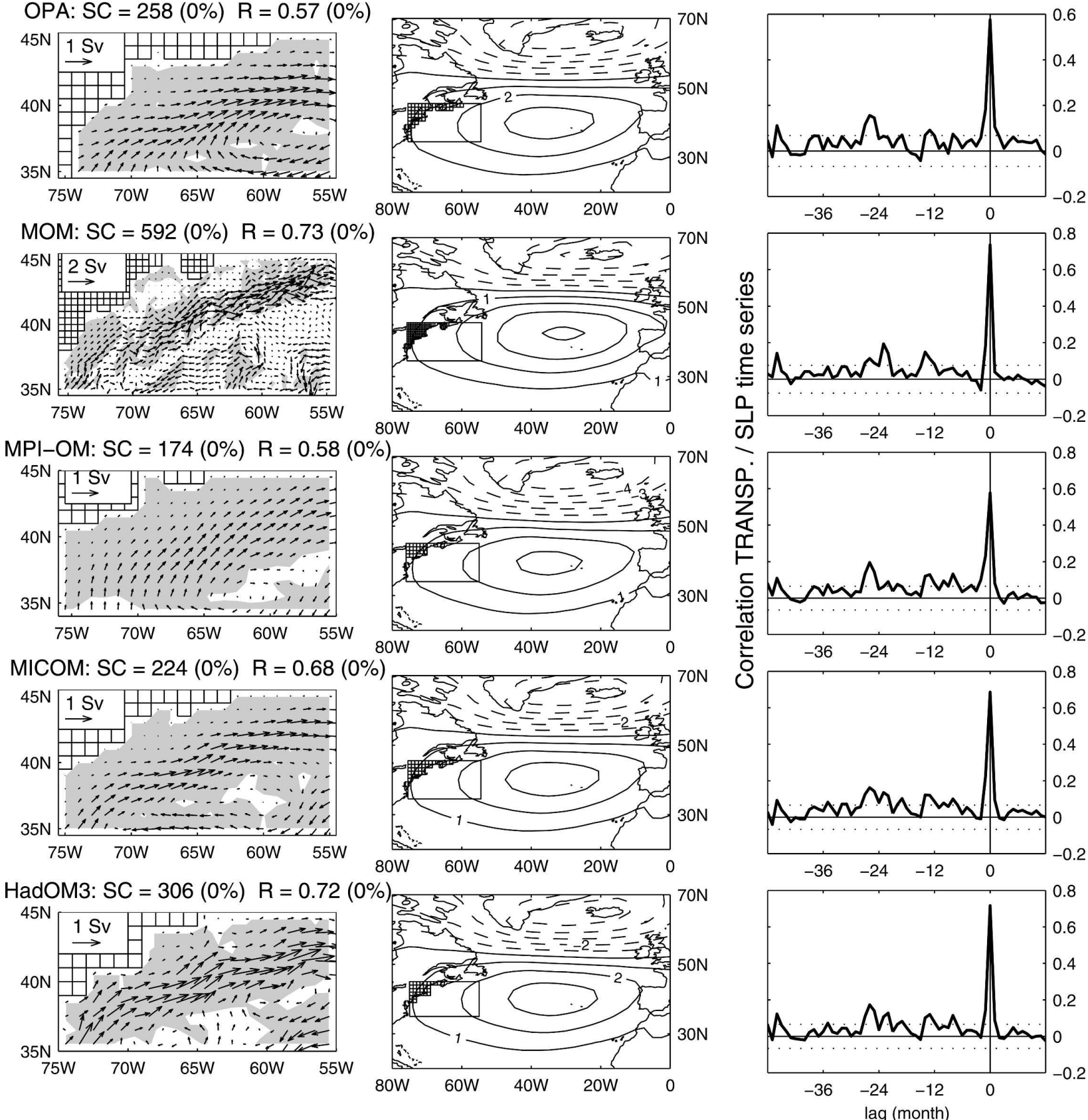

FIG. 4. First MCA modes between (left) monthly anomalies in the total transport in the Gulf Stream region (homogeneous maps) and (middle) SLP anomalies in the North Atlantic (heterogeneous maps; hPa) at lag 0 . The estimated significance level is given in parenthesis for the square covariance (SC) and correlation $r$. The time series are normalized so that the figures indicate typical magnitudes. (right) The cross correlation between the two MCA time series, with $10 \%$ significant level (dotted) is shown. NAO leads for negative lags.

indeed shows a sharp peak at lag 0 , consistent with the fast adjustment of barotropic flows and the slight autocorrelation of the NAO time series. The two time series are uncorrelated when the ocean leads (positive lag), but when it lags by between about 8 months and $3 \mathrm{yr}$ (negative lag), the correlation, albeit very small, remains mostly positive. In addition to this broad, weak maximum, in all models there are small peaks near lag $-13,-25$, and -46 . As shown in Fig. 5, these peaks reflect small corresponding peaks in the NAO autocor- 


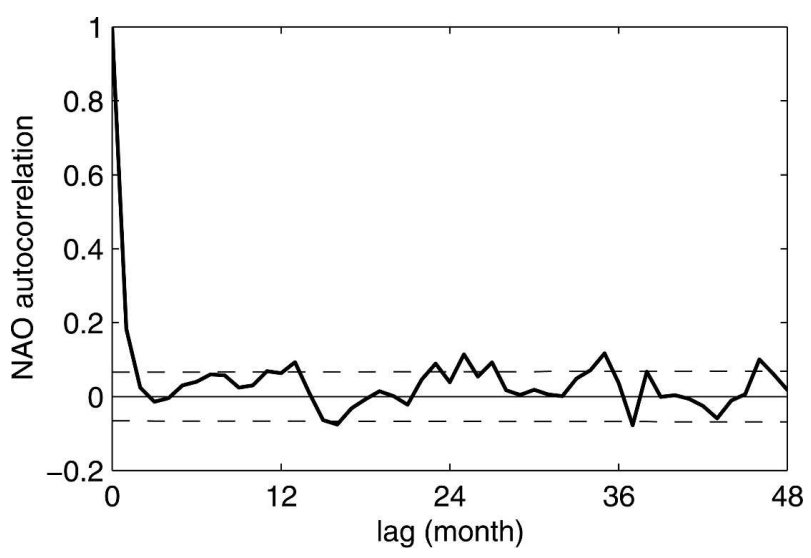

FIG. 5. Autocorrelation of the NAO (thick solid) and 10\% significant correlation level (dashed).

relation function, but note that the latter does not remain as positive at a large lag as the cross correlation in Fig. 4. Because the lags of positive correlation correspond to a significant correlation between the NAO and the baroclinic transport (see below), we suggest that they most reflect a weak coupling between the barotropic and baroclinic response, presumably because of the influence of topography and mean vertical shear.

The lagged MCA was also performed between SLP and baroclinic transport anomalies. We have chosen to represent the maximum covariance patterns for each model (except MOM) at lag -24 (Fig. 6). The modes are highly significant, but in MOM the correlation was weak and only $38 \%$ significant in square covariance, presumably because of the shorter sample and the higher resolution of the model, which increases the noise level. However, lag -26 in MOM was more significant and has been chosen in Fig. 6. In all cases, the SLP pattern (Fig. 6, middle) again corresponds to the NAO. The transport patterns show (Fig. 6, left) that a positive phase of the NAO is followed in each model by an increase of the northeastward baroclinic transport near the western boundary in the following years. The baroclinic transport patterns are not unlike the barotropic ones, except that the GS is closer to the coast and there is a more pronounced anticyclonic gyre in MPI$\mathrm{OM}$ and HadOM3. The cross-correlation function between the two MCA time series (Fig. 6, right) illustrates that the baroclinic response is seen for lags up to several years, with a maximum correlation when NAO leads by about 2 yr. Moreover, a large narrow peak, albeit smaller than that in Fig. 4, is found at lag 0. This is consistent with the fast barotropic adjustment of the subtropical gyre to wind stress forcing and the slower baroclinic one predicted by linear theories, together with the weak coupling between barotropic and baro- clinic response suggested above. Similar results were obtained when using yearly means in the lagged MCA (not shown). A strong covariability between the NAO and the barotropic transport was found at lag 0 , and a weaker one at lags -1 to -3 , while the covariability between the NAO and the baroclinic transport was maximum at lag -2 in all models except for MPI-OM (lag -1$)$, although lag -1 and -3 were also significant in most cases.

The time it takes for a first mode baroclinic Rossby wave to cross the Atlantic basin at $30^{\circ}$ and $40^{\circ} \mathrm{N}$ should be about 8 and $15 \mathrm{yr}$, respectively, which is much longer than the 2-yr lag found here for the maximum covariability between the NAO and the GS transport. However, as shown in Fig. 7, the Ekman pumping $\nabla \times(\tau / f)$ ( $\tau$ is the wind stress and $f$ is the Coriolis parameter) associated with the NAO has a complex spatial pattern, and wind stress forcing maxima occur in the interior of the gyre, resulting in shorter propagation time, as in the North Pacific (Fu and Qiu 2002). We searched for baroclinic Rossby wave propagation in one of the models, namely, OPA (lack of time prevented us from similarly considering the other models). The clearest results were found by using Hovmoeller diagram for the lagged correlation between the NAO in February and the baroclinic zonal transport at a later time (similar, but noisier results were found with the meridional baroclinic transport). Although using the NAO index only once per year decreases the available degrees of freedom, it enhances the signal-to-noise ratio because the NAO amplitude is largest in February and rapidly decreases in the following months, which leads to less interference with NAO events taking place later in the year. The correlation is shown for two latitudes in Fig. 8. At $27^{\circ} \mathrm{N}$ (left), a westward-propagating increase in the zonal transport starts around $20^{\circ} \mathrm{W}$ near the eastern boundary, where there is a local (positive) maximum of the wind stress curl (Fig. 7). In a simple Sverdrup theory framework, the latter should move water northeastward, and the perturbation should propagate westward at the speed of the first baroclinic Rossby mode. The propagation is indeed consistent with the 3.5 $\mathrm{cm} \mathrm{s}^{-1}$ westward phase speed (Fig. 8, thick black) calculated by Chelton et al. (1998) for the North Atlantic and as given by Osychny and Cornillon (2004). Another westward-propagating signal can also be seen between $50^{\circ}$ and $55^{\circ} \mathrm{W}$, slightly east of a weaker wind stress curl maximum, but only at a short lag, presumably because it rapidly reaches the broad western boundary return flow. At $32^{\circ} \mathrm{N}$, the wind stress curl is positive near $20^{\circ} \mathrm{W}$ and negative further west. Thus, we expect an increase in the zonal transport near the African coast and a decrease elsewhere, as seen in Fig. 8 (right). Note that 
BAROCLIN. TRANSP. OPA: $\mathrm{SC}=13(2 \%) \mathrm{R}=0.18(2 \%)$

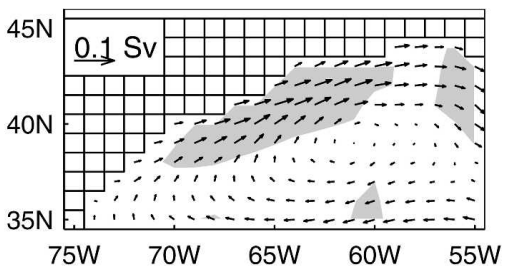

MOM: SC $=52(0 \%) R=0.29(18 \%)$

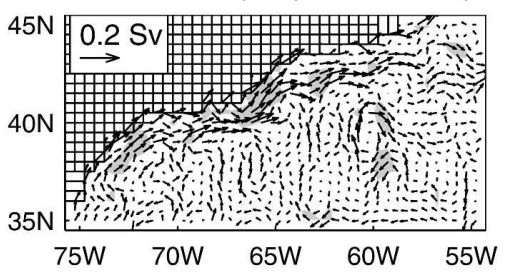

MPI-OM: SC $=19(0 \%) \mathrm{R}=0.19(0 \%)$

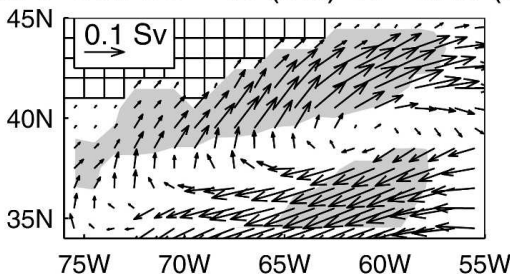

$75 \mathrm{~W} \quad 70 \mathrm{~W} 65 \mathrm{~W} \quad 60 \mathrm{~W} 55 \mathrm{~W}$

MICOM: SC $=14(0 \%) \mathrm{R}=0.21(0 \%)$
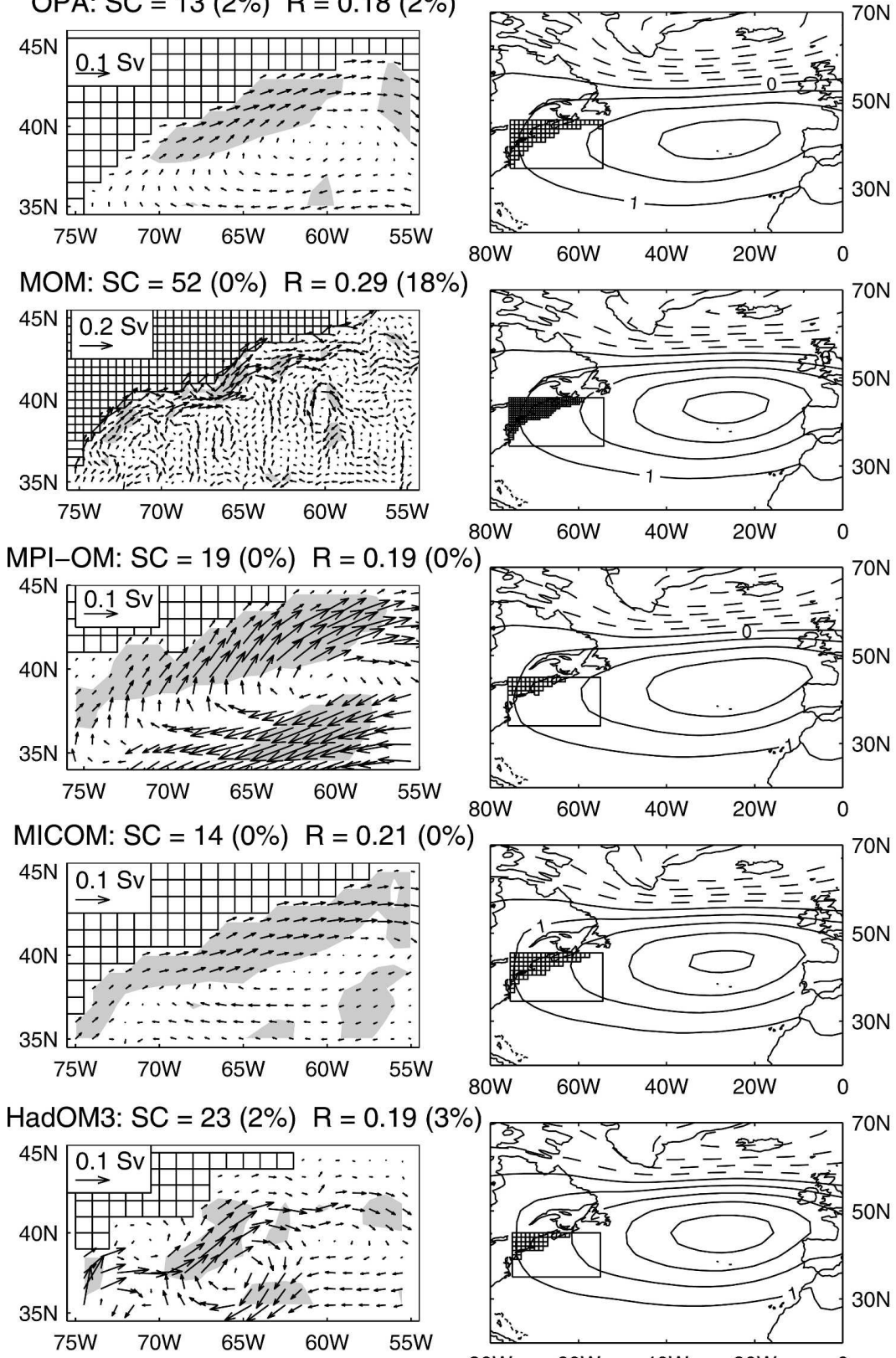

$80 \mathrm{~W}$

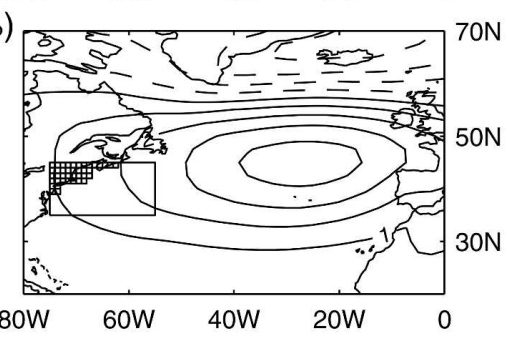

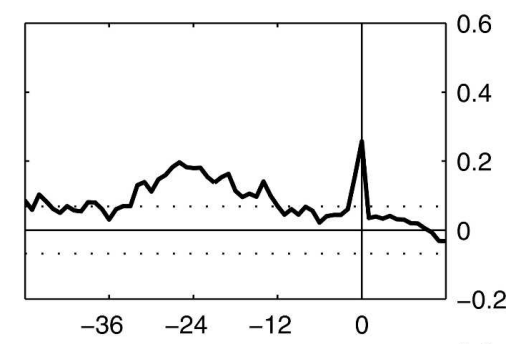
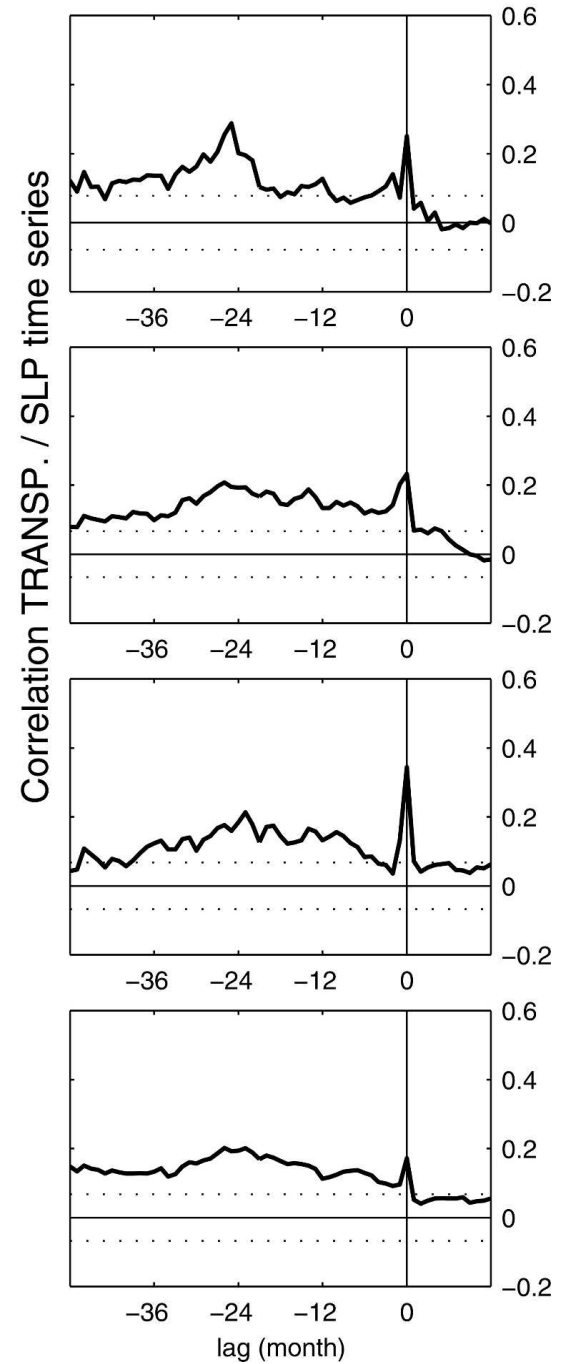

FIG. 6. Same as in Fig. 4, but for the transport between 200 and $600 \mathrm{~m}$ when the SLP leads by 24 months.

the maximum negative correlation (westward flow) is found midbasin suggesting a topographic influence and consistent with the high and low variance of lowfrequency sea surface height fluctuations observed in satellite data west and east of the mid-Atlantic ridge, respectively (Osychny and Cornillon 2004). The signal seems to propagate westward at a speed roughly consistent with the $2.5 \mathrm{~cm} \mathrm{~s}^{-1}$ Rossby wave speed of Chel- ton et al. (1998), reaching the boundary current region after about 2 yr. After this delay, the perturbation becomes nearly stationary, suggesting more complex dynamics on long time scales. Although no propagation could be clearly detected at latitudes higher than $35^{\circ} \mathrm{N}$, the results are broadly consistent with the delay seen in Fig. 6, or with the 3-yr delay found for the intensification of the subtropical gyre by Eden and Willebrand (2001). 


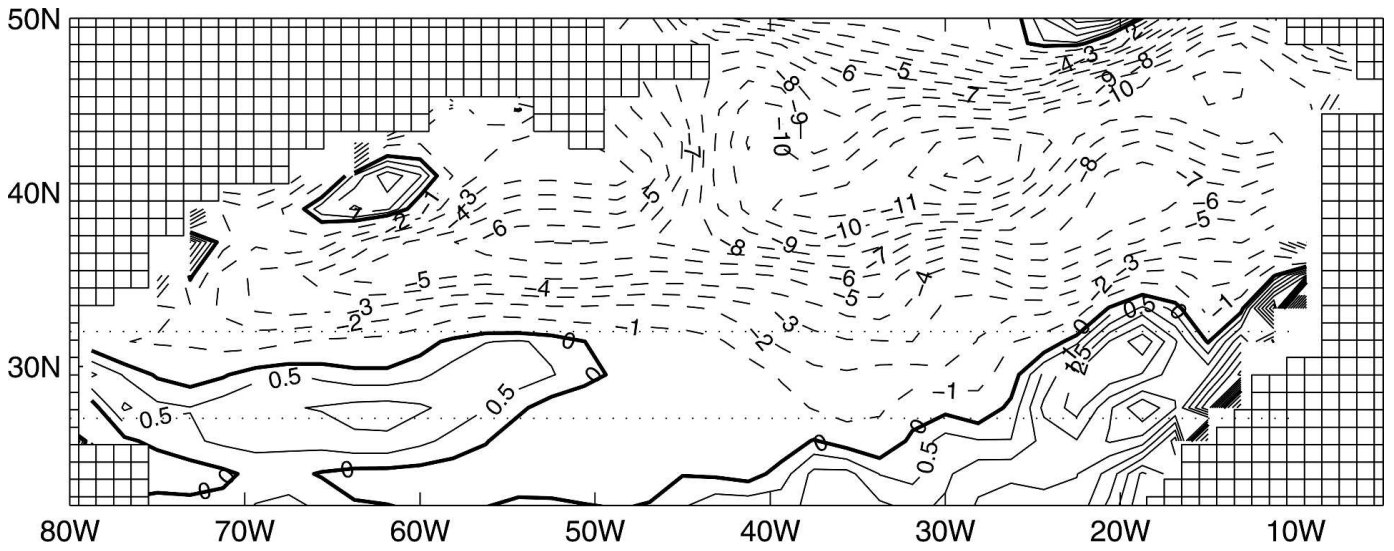

FIG. 7. Ekman pumping $\left(\times 10^{-8} \mathrm{~m} \mathrm{~s}^{-1}\right)$ associated with the normalized February NAO time series. Intervals are 0.5 for positive (solid) and 1 for negative (dashed). Dotted lines indicate the latitudes of $27^{\circ}$ and $32^{\circ} \mathrm{N}$.

\section{Link between GST index and meridional overturning circulation}

Because the AMOC should significantly contribute to the net mass transport in the GS region, part of the changes in the GS transport could be linked to the variability of the AMOC. In addition, the subtropical gyre and the thermohaline circulation may respond on rather comparable time scales to the NAO forcing. Hence, we have compared the GS and the AMOC behaviors in the OGCM simulations. The AMOC index was defined as the yearly averaged maximum of the Atlantic meridional streamfunction north of $30^{\circ} \mathrm{N}$. The ensemble mean was used for MPI-OM and MICOM, although there is some dispersion between the runs, as discussed for MICOM by Bentsen et al. (2004) and illustrated in Fig. 9 (top), which shows the four different AMOC index time series for MICOM. Note, in particular, the large differences in the AMOC index during the first $5 \mathrm{yr}$ or so of the simulation, and the somewhat more coherent behavior thereafter, but without any evidence of convergence with increasing simulation length.

It is beyond the scope of this paper to discuss the mechanisms of the modeled AMOC changes in the different models. However, Bentsen et al. (2004) have shown that the decadal variability of the AMOC in the MICOM simulations were governed by convective mixing in the Labrador and the Irminger Seas, and that the former (but not the latter) was mainly determined by NAO forcing. Haak et al. (2003) suggested that the AMOC variability was mainly driven by the NAO in the MPI-OM simulations. In addition, they showed that the great salinity anomalies observed in the Labrador Sea, which were well reproduced by the model and remotely forced by the wind in the Arctic, had only a minor impact on the strength of the AMOC.
Figure 9 (four lowest panels) shows the AMOC (solid line) and GST (dashed line) indices for each simulation, as well as their correlation $r$. In three of the four simulations, $r$ is 0.37 or more, while $r$ is only 0.06 in the fourth one. However, $r$ rises to 0.36 in the latter when the first $3 \mathrm{yr}$ are removed, suggesting a strong initial imbalance. In any case, the AMOC-GST correlation depends on the initial conditions, and caution is required when interpreting results based on a single simulation per model.

For each model, the baroclinic transport was projected onto the AMOC index (Fig. 10). In most cases, the correlation between the baroclinic transport and the AMOC is highly significant and the projection clearly shows that a stronger AMOC corresponds to an increased transport in the northwestern Atlantic. Note that the patterns in Figs. 2 and 10 are somewhat different, because the AMOC is associated with a broader and more uniform northeastward flow than the GST index, without return flow in the southeastern part of the domain.

The time behavior of the AMOC is shown for each model in Fig. 11 (solid line). Both MPI-OM and MICOM show a fast AMOC weakening until the late 1950s followed by a slow acceleration until the late 1990s. The other models show slightly different behaviors. The slow acceleration of the AMOC is seen in OPA, albeit only until the early 1990s, but not the initial AMOC weakening. MOM shows an initial AMOC weakening, but a decade later than MPI-OM and MICOM, also followed by a slow increase. Again, HadOM3 behaves differently. The GST index is also represented for each model in Fig. 11 (dashed line; left column). It correlates well with the AMOC in MICOM, MOM, and, to a lesser extent, in HadOM3. On the other hand, the agreement between GST and AMOC 


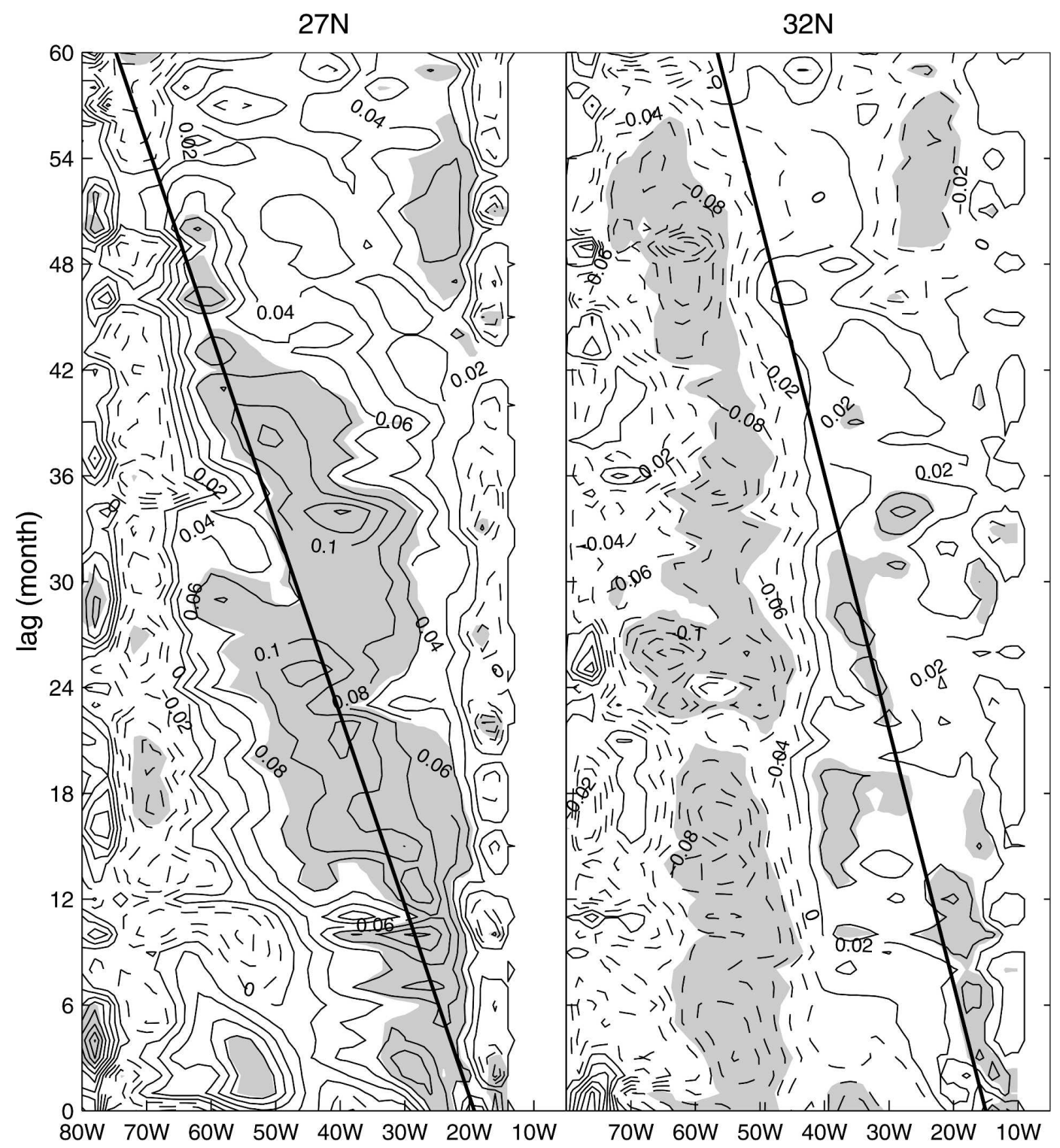

FIG. 8. Lagged cross correlation between NAO anomalies in February and monthly anomalies in the zonal transport at (left) $27^{\circ}$ and (right) $32^{\circ} \mathrm{N}$ in OPA (contour interval 0.02 , negative values are dashed). Gray shading indicates $10 \%$ significance. The thick line indicates the theoretical Rossby waves velocity.

indices is poor in MPI-OM and in OPA. As discussed before, the GS position is not very well defined in the models because of the width of the GS and, in some cases, the close proximity to the coast.

It is thus of interest to also compare the AMOC indices with the observed changes in the GST position, as is in Fig. 11 (right column), which shows that in most cases the AMOC index compares better with the observed GST index than with the simulated one. The correlation is as high as 0.73 for the MICOM ensemble mean, and it is now 0.5 for MPI-OM, reflecting in both cases that the GS index shows a fast southward shift until the early 1960s and a slow northward shift thereafter. The correlation is also above 0.5 for OPA and significant in HadOM3, so that the AMOC is only poorly correlated with the observed GS changes in MOM. Note that the observed time series starts $6 \mathrm{yr}$ after the beginning of the model simulations, so that the correlation between the GST and AMOC indices should be less affected by spinup problems, except for the MOM simulation that started in 1958. A higher correlation of the AMOC index with the observed GST index was also found in each of the individual MICOM simulations, as indicated in Fig. 9 (in parentheses). 

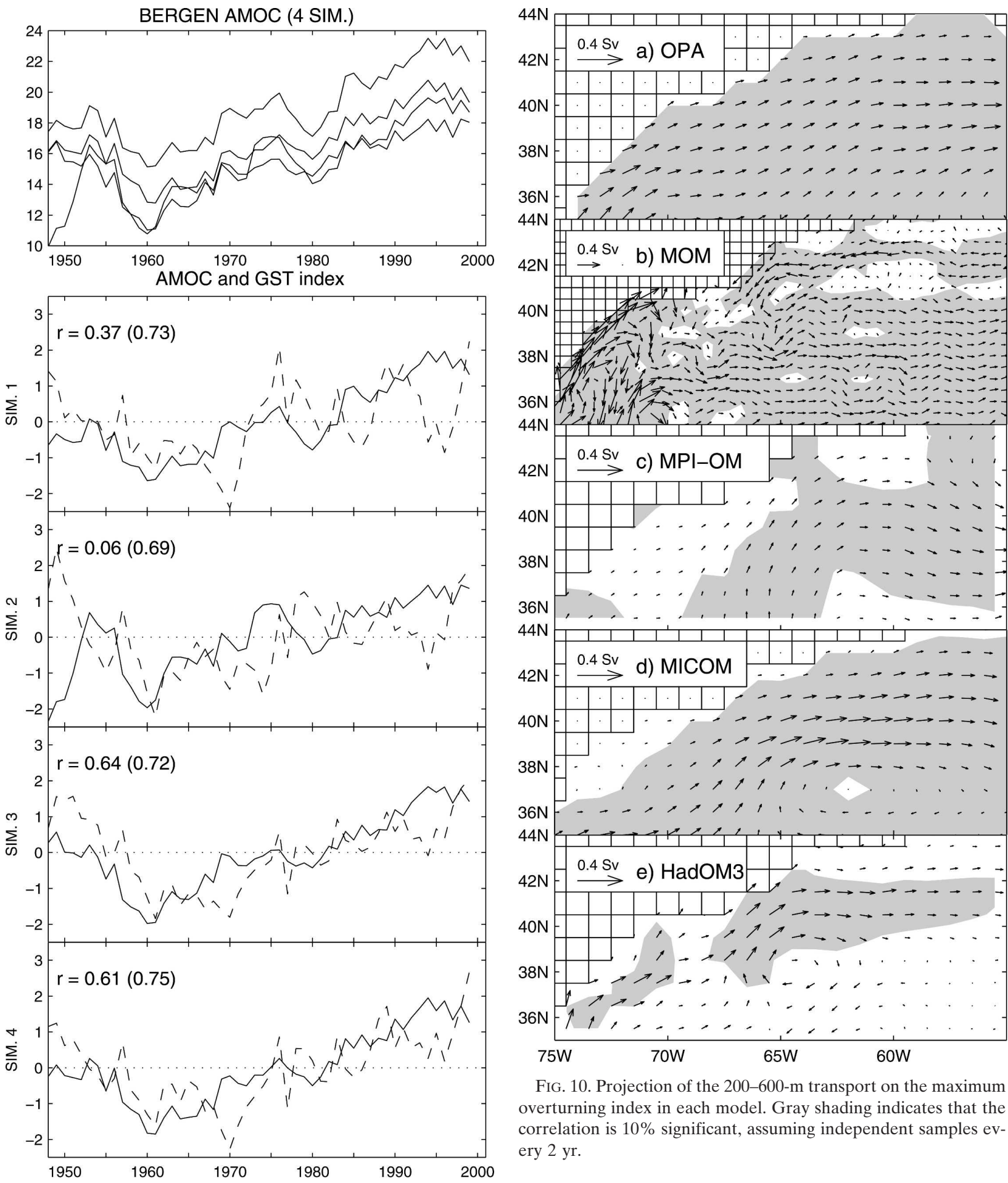

FIG. 10. Projection of the 200-600-m transport on the maximum overturning index in each model. Gray shading indicates that the correlation is $10 \%$ significant, assuming independent samples every 2 yr.

FIG. 9. (top) Time series of the AMOC in the four MICOM simulations (Sv). For each simulation, normalized time series of the AMOC (solid) and GST index (dashed), and correlation coefficient $r$. Correlation between the AMOC and the observed GST index (in parentheses).

In summary, the analysis suggests that the northward shift and the intensification of the GS are associated with a stronger AMOC. This agrees with Eden and Jung (2001), who found that an increase in the AMOC resulting from NAO forcing was accompanied at interdecadal time scale by an increase in the strength of the 


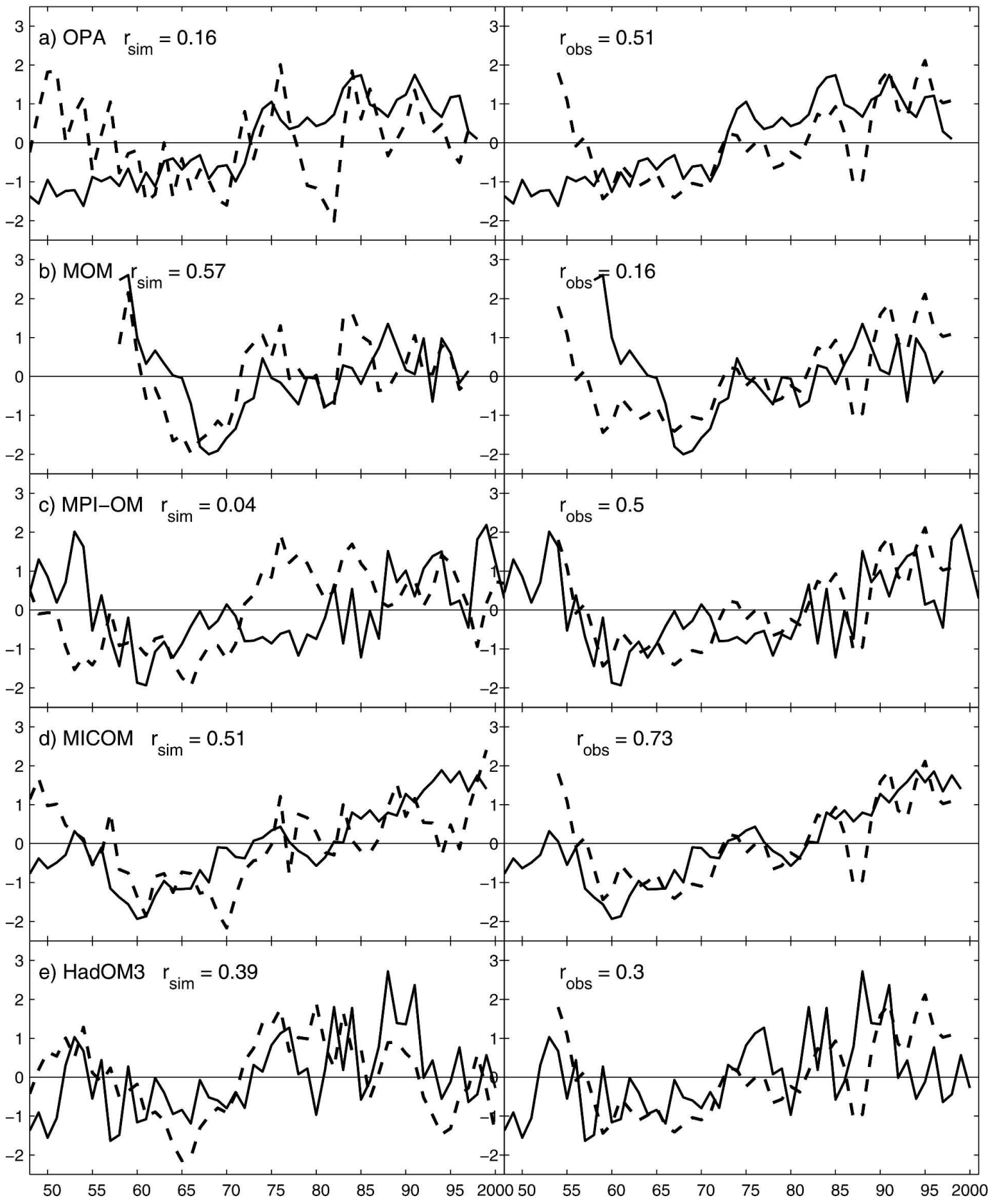

FIG. 11. Time series of the AMOC (solid line) and the GST index (dashed) in the (left) model simulation and (right) observations. Ensemble means are used for MPI-OM and MICOM. The correlation between the two series is indicated.

subpolar and subtropical gyre circulation, and vice versa. They suggested that the main driving mechanism was the surface heat flux forcing, but our results also point to wind forcing as a controlling factor of the GS changes. On the other hand, our relation between the AMOC and the GS shift is opposite that in the sensitivity studies of Thompson and Schmitz (1989), Gerdes and Köberle (1995), and Spall (1996), who found that a stronger DWBC would lead to a southward displacement of the GS. The difference might be due to the weakness of the DWBC in non-eddy-resolving models, which are unable to correctly simulate its impact on the GS system, or it might simply be due to the particular setting of the sensitivity studies. Clearly, the relation 
between the AMOC and the GS needs to be investigated further using eddy-resolving models forced by realistic fields.

\section{Summary and discussion}

Using simulations with five non-eddy-resolving OGCMs forced by air-sea fluxes derived from the NCEP-NCAR reanalysis, we have investigated the relation between the changes in the GS, the atmospheric forcing, and the AMOC. In nearly all of the models, although the temperature gradient associated with the GS is much too smooth and the GS is much too weak, the temperature at the 200-m depth along the mean GS axis was found to behave similarly to that observed (FCJD), and to also be well correlated with the NAO, with a northward GS shift lagging a positive NAO phase by $0-2 \mathrm{yr}$, and conversely a southward GS shift lagging a negative NAO phase. In each model, a positive (negative) NAO phase leads to an increase (decrease) in the GS transport. Two dominant time scales characterize the response of the model GS transport to the NAO forcing: a fast time scale (less than 1 month) for the barotropic component, and a slower one (about $2 \mathrm{yr}$ ) for the baroclinic component. In addition, the two components were weakly coupled, presumably because of the influence of topography and vertical shear. The model GS response thus seems broadly consistent with a linear adjustment to the changes in the wind stress curl, and some evidence was indeed found in the southern part of the subtropical gyre that baroclinic Rossby waves were driven by the Ekman pumping associated with the NAO variability. As in the North Pacific (Fu and Qiu 2002), the forcing primarily occurs in the interior of the gyre and the influence of the eastern boundary seems to be minor, thereby explaining the relatively short time lag found between the NAO forcing and the GS response. Some topographic influence was also detected.

The maximum barotropic GS transport anomalies induced by the wind stress curl anomaly associated with the NAO ranges between about 4 and $8 \mathrm{~Sv}$, depending on the model. This is of the order of the interpentadal changes estimated from hydrographic observations by Sato and Rossby (1995), but substantially smaller than the $30 \mathrm{~Sv}$ estimated by Greatbach et al. (1991). However, doubts have been raised on the reliability of the latter calculation (Cane et al. 1998).

The good agreement between the modeled and the observed shifts in the GS position may seem surprising because non-eddy-resolving models cannot represent the inertial recirculation gyres and underestimate the deep flow and thus the topographic influence, and thereby strongly underestimate the GS transport. Yet, a rather similar relation between GS changes and NAO forcing is found in the eddy-resolving simulation of Penduff et al. (2004), possibly reflecting a broad similarity in the adjustment time of linear and nonlinear oceans to wind forcing. Direct wind forcing is not the sole mechanism determining the GS position, however, because simulations made with a given model under different initial conditions but with the same wind forcing showed a substantial dispersion that did not decrease with the length of the simulation. This suggests that basin-scale circulation changes must also affect the GS position, consistent with the fact that at a low frequency the GS shifts were rather well correlated in most models with the changes in the AMOC. Indeed, a stronger (weaker) and more northerly (southerly) GS was found when the AMOC was anomalously large (small). Again, the AMOC showed some dependence on the initial conditions, which only decreased during the first few years of the run, but not thereafter. Interestingly, a higher correlation was found when the observed changes of the GS position were used in the comparison. This presumably occurs in part because the GS is too broad and too close to the coast in the models, so that its position is not as well defined as in the observations. Also, the observed time series starts 6 yr after the beginning of the simulations, which are by then less affected by the lack of knowledge of the initial conditions. The latter may explain why the correlation between the GS variability and the changes in the AMOC is particularly strong for the two models whose AMOC index is based on ensemble averages, and are thus less likely to be affected by an initial imbalance.

The good correlation between the GS and the model AMOC changes seems to reflect an inherent coupling between the thermohaline and the wind-driven circulation, as in Eden and Jung (2001), but observations are needed to determine if the simulated AMOC changes are realistic. In addition, the underlying physics remains to be understood. In the models, the correlation between the GS and the AMOC could happen because the AMOC significantly contributes to the GS transport, or because the NAO variability drives the winddriven and the thermohaline circulations on similar time scales. Direct interaction between the GS and the DWBC is unlikely to play a significant role here because coarse-resolution models strongly underestimate the DWBCs. In addition, sensitivity studies on their impact on the GS suggest an opposite relation with the AMOC - a stronger DWBC leading to a southward shift in the GS path (e.g., Gerdes and Köberle 1995) although this depends on the vertical distribution of the DWBC changes (Spall 1996). A reviewer of this paper 
has insisted that we quote Latif et al.'s (2004) reconstruction of the AMOC variations based on SST observations and the correlation in a coupled model (whose oceanic component is MPI-OM) between the AMOC and SST anomalies in the North Atlantic. In this exercise, the AMOC is high in the early 1950s, decreases until the mid-1970s, and increases again until 1998, not really unlike the MPI-OM behavior in Fig. 11, except that the minimum occurs around 1960. However, we feel that such reconstruction should not be used as a proxy to the observations before it has been carefully tested.

It should be remarked that there were significant differences in the GS and AMOC behavior of the five models. However, they were not larger than some of the differences between two simulations with the same model but different initial conditions. Because ensemble simulations were only available for two OGCMs, no model intercomparison was attempted. Note that we avoided comparing our results with coupled model simulations because the oceanic components of these models are similar (in some cases identical) to the OGCMs considered here, and they thus have similar flaws. In addition, the coupled models are affected by the biases and deficiencies of their atmospheric and other components. Further understanding of the relation between the GS, the atmosphere and the AMOC is more likely to be gained by considering simulations with higher-resolution OGCMs, if possible eddy-resolving ones, and by a more detailed comparison with the observations.

Acknowledgments. This research was supported by the PREDICATE project of the European Community, and for M. Bentsen by the Research Council of Norway through RegClim, NOClim, and the Programme of Supercomputing. We thank the anonymous reviewers for their helpful comments.

\section{REFERENCES}

Anderson, D. L. T., and A. E. Gill, 1975: Spin-up of a stratified ocean, with applications to upwelling. Deep-Sea Res., 22, 583586

Bentsen, M., H. Drange, T. Furevik, and T. Zhou, 2004: Simulated variability of the Atlantic meridional overturning circulation. Climate Dyn., 22, 701-720.

Bleck, R., C. Rooth, D. Hu, and L. T. Smith, 1992: Salinity-driven thermohaline transients in a wind- and thermohaline-forced isopycnic coordinate model of the North Atlantic. J. Phys. Oceanogr., 22, 1486-1515.

Bretherton, C.-S., C. Smith, and J.-M. Wallace, 1992: An intercomparison of methods for finding coupled patterns in climate data. J. Climate, 5, 541-560.

Cane, M. A., V. Kamenkovich, and A. Krupitsky, 1998: On the utility and disutility of JEBAR. J. Phys. Oceanogr., 28, 519526.

Cessi, P., 1990: Recirculation and separation of boundary currents. J. Mar. Res., 48, 1-35.

Chelton, D. B., R. A. deSzoeke, M. G. Schlax, K. El Naggar, and N. Siwertz, 1998: Geographical variability of the first baroclinic Rossby radius of deformation. J. Phys. Oceanogr., 28, 433-460.

Cox, M. D., 1985: An eddy resolving numerical model of the ventilated thermocline. J. Phys. Oceanogr., 15, 1312-1324.

Curry, R. G., and M. McCartney, 2001: Ocean gyre circulation changes associated with the North Atlantic Oscillation. $J$. Phys. Oceanogr., 31, 3374-3400.

Dewar, W. K., 2003: Nonlinear midlatitude ocean adjustment. $J$. Phys. Oceanogr., 33, 1057-1082.

Eden, C., and T. Jung, 2001: North Atlantic interdecadal variability: Oceanic response to the North Atlantic Oscillation (1865-1997). J. Climate, 14, 676-691.

— , and J. Willebrand, 2001: Mechanisms of interannual to decadal variability in the North Atlantic circulation. J. Climate, 14, 2266-2280.

Ezer, T., and G. L. Mellor, 1992: A numerical study of the variability and the separation of the Gulf Stream induced by surface atmospheric forcing and lateral boundary flow. $J$. Phys. Oceanogr., 22, 660-682.

— - - and R. J. Greatbach, 1995: On the interpentadal variability of the North Atlantic Ocean: Model simulated changes in transport, meridional heat flux and coastal sea level between 1955-1959 and 1970-1974. J. Geophys. Res., 100, $10559-10566$.

Frankignoul, C., G. de Coëtlogon, T. M. Joyce, and S. Dong, 2001: Gulf Stream variability and ocean-atmosphere interactions. J. Phys. Oceanogr., 31, 3516-3529.

Fu, L.-L., and B. Qiu, 2002: Low-frequency variability of the North Pacific Ocean: The roles of boundary- and wind-driven baroclinic Rossby waves. J. Geophys. Res., 107, 3220, doi:10.1029/2001JC001131.

Gangopadhyay, A., P. Cornillon, and D. R. Watts, 1992: A test of the Parsons-Veronis hypothesis on the separation of the Gulf-Stream. J. Phys. Oceanogr., 22, 1286-1301.

Gerdes, R., and C. Köberle, 1995: On the influence of DSOW in a numerical model of the North Atlantic general circulation. J. Phys. Oceanogr., 25, 2624-2642.

— A. Biastoch, and R. Redler, 2001: Salt balance of the Gulf Stream in a regional model: Implications for climate variability. Climate Dyn., 18 (1/2), 17-27.

Gordon, C., C. Cooper, C. A. Senior, H. Banks, J. M. Gregory, T. C. Johns, J. F. B. Mitchell, and R. A. Wood, 2000: The simulations of SST, sea ice extents and ocean heat transports in a version of the Hadley Centre coupled model without flux adjustments. Climate Dyn., 16, 147-168.

Greatbach, R. J., A. F. Fanning, A. D. Goulding, and S. Levitus, 1991: A diagnosis of interpentadal circulation changes in the North Atlantic. J. Geophys. Res., 96, 22 009-22 023.

Haak, H., J. Jungclaus, U. Mikolajewicz, and M. Latif, 2003: Formation and propagation of great salinity anomalies. Geophys. Res. Lett., 30, 1473, doi:10.1029/2003GL017065.

Holland, W. R., and A. D. Hirschman, 1972: A numerical calculation of the circulation in the North Atlantic Ocean. J. Phys. Oceanogr., 2, 336-354.

Jiang, S., F.-F. Jin, and M. Ghil, 1995: Multiple equilibria, periodic, and aperiodic solutions in a wind-driven, double-gyre, shallow-water model. J. Phys. Oceanogr., 25, 764-786. 
Joyce, T. M., C. Deser, and M. Spall, 2000: The relation between decadal variability of subtropical mode water and the North Atlantic Oscillation. J. Climate, 13, 2550-2569.

Kalnay, E., and Coauthors, 1996: The NCEP/NCAR 40-Year Reanalysis Project. Bull. Amer. Meteor. Soc., 77, 437-471.

Kelly, K., 1991: The meandering Gulf Stream as seen by the Geosat altimeter: Surface transport, position and velocity variance from $73^{\circ}$ to $46^{\circ} \mathrm{W}$. J. Geophys. Res., 96, 16 721-16 738 .

Kelly, K. A., and S. T. Gille, 1990: Gulf Stream surface transport and statistics at $69^{\circ} \mathrm{W}$ from the Geosat altimeter. J. Geophys. Res., 95, 3149-3161.

Latif, M., and Coauthors, 2004: Reconstructing, monitoring, and predicting multidecadal-scale changes in the North Atlantic thermohaline circulation with sea surface temperature. J. Climate, 17, 1605-1614.

Levitus, S., 1994: World Ocean Atlas 1994. National Oceanographic Data Center Informal Rep. 13, CD-ROM.

Madec, G., P. Delecluse, M. Imbard, and C. Lévy, 1998: OPA8.1 ocean general circulation model reference manual. Notes du pôle de modélisation IPSL 11, $91 \mathrm{pp}$.

Marsland, S. J., H. Haak, J. H. Jungclaus, M. Latif, and F. Röske, 2003: The Max-Planck-Institute global ocean/sea ice model with orthogonal curvilinear coordinates. Ocean Modell., 5, 91-127.

Masina, S., P. Di Pietro, and A. Navarra, 2004: Interannual-todecadal variability of the North Atlantic from an ocean data assimilation system. Climate Dyn., 23, 531-536.

Nurser, A. J. G., and R. G. Williams, 1990: Cooling Parsons' model of the separated Gulf Stream. J. Phys. Oceanogr., 20, 1974-1979.

Osychny, V., and P. Cornillon, 2004: Properties of Rossby waves in the North Atlantic estimated from satellite data. J. Phys. Oceanogr., 34, 61-76.

Parsons, A. T., 1969: A two-layer model of Gulf Stream separation. J. Fluid Mech., 39, 511-528.

Penduff, T., B. Barnier, W. Dewar, and J. O'Brien, 2004: Dynamical response of the oceanic eddy field to the North Atlantic
Oscillation: A model-data comparison. J. Phys. Oceanogr. 34, 2615-2629.

Rossby, H. T., and T. Rago, 1985: Hydrographic evidence for seasonal and secular change in the Gulf Stream. IOC Tech. Rep. $30,25-28$.

Sato, O., and T. Rossby, 1995: Seasonal and low frequency variations in dynamic height anomaly and transport of the Gulf Stream. Deep-Sea Res., 42, 149-164.

Sirven, J., 2005: Response of the separated western boundary current to harmonic and stochastic wind stress variations in a 1.5-layer ocean model. J. Phys. Oceanogr., 35, 1341-1358.

Spall, M. A., 1996: Dynamics of the Gulf Stream/deep western boundary currents crossover. Part II: Low frequency internal oscillations. J. Phys. Oceanogr., 26, 2152-2168.

Taguchi, B., S. P. Xie, H. Mitsudera, and A. Kubokawa, 2005: Response of the Kuroshio Extension to Rossby waves associated with the 1970s climate regime shift in a high-resolution ocean model. J. Climate, 18, 2979-2995.

Taylor, A. H., and J. A. Stephens, 1998: The North Atlantic Oscillation and the latitude of the Gulf Stream. Tellus, 50A, 134-142.

_ , and A. Gangopadhyay, 2001: A simple model of interannual displacements of the Gulf Stream. J. Geophys. Res., 106, 13 849-13 860.

Thompson, J. D., and W. J. Schmitz, 1989: A limited area model of the Gulf Stream: Design, initial experiments and modeldata intercomparison. J. Phys. Oceanogr., 19, 791-814.

Tracey, K. L., and D. R. Watts, 1986: The Gulf Stream dynamics experiment: Inverted echo sounder data report for the April 1983 to June 1984 deployment period. University of Rhode Island GSO Tech. Rep. 86-4, 236 pp.

Veronis, G., 1973: Model of the World Ocean circulation: I. winddriven, two layer. J. Mar. Res., 31, 228-288.

von Storch, H., and F. W. Zwiers, 1999: Statistical Analysis in Climate Research. Cambridge University Press, 494 pp.

Zlotnicki, V., 1991: Sea level differences across the Gulf Stream and Kuroshio Extension. J. Phys. Oceanogr., 21, 599-609. 